International Journal of English Literature and Social Sciences
Vol-6, Issue-2; Mar-Apr, 2021

\title{
How to Read and Understand the Value Determinism Theory of the media1? A semantic Structural Approach
}

\author{
Nassir Bouali, Alaa Makki
}

Communication Department, College of communication, University of Sharjah, United Arab Emirates

Received: 11 Dec 2020; Received in revised form: 11 Feb 2021; Accepted: 01 Mar 2021; Available online: 20 Mar 2021

(C)2021 The Author(s). Published by Infogain Publication. This is an open access article under the CC BY license

(https://creativecommons.org/licenses/by/4.0/).

\begin{abstract}
The value determinism theory of media is one of contemporary normative communication theories that is associated with the writing of Abderrahmane Azzi since the mid-1980s. This study identifies and clarifies the perspective of the theory based on a structural approach according to the following axes: priory of the theory over its parts; priority of the theory relationship over the parts; theory as a context; principle of synchronization and diachronization of the theory. For these characteristics the researcher tried to read and understand this theory. The study further delineates the position of VDT with other communication theories. Finally, the study states the main conceptual tools that made VDT a major trend in communication research in the Arab-Islamic region and abroad.
\end{abstract}

Keywords-Determinism, Value, Media, Structuralism and semiotic.

\section{INTRODUCTION}

This study is not related to the epistemological context of the value determinism theory (VDT) of the media, which needs time to read carefully in the researches and studies of Abderrahmane $\mathrm{Azzi}^{2}$, and who are from researchers related to his theory context, until the theory becomes clear and less unambiguous. This study is about the methodology of reading and understanding the perspective structure of the theory. Azzi's research, as we have already indicated in a previous study in Arabic and French languages, requires that the readers possess a high intellectual and the same scientific trend(that is to say from the same ideas with the founder of theory) in order to be able to decode the symbols, expressions and meanings of the theory as the following concepts: Culture(New approach), Media Time, Media Space, Media imagination, Media and Symbolic Capital, Media Fear, Ethical Responsibility etc. These concepts are attached to the theory (VDT) of media and they describe, analyze and explain the reality of Arab and Muslim media as well.

In short, this conceptual paper is about key concepts or the methodology to read and understand this theory. The careful reader of the theory observes the use of the expression of the "keys" as plural and not singular, because the approaches to this theory are multiple. Is it possible now to read and understand the theory from the semantic structural approach? In other words, does the semantic structural approach help us to understand the value determinism theory (VDT) of media?

The attraction between culture as a real world and the means of communication as a symbolic world:

(Azzi Abdurrahman, an invitation to understand the value determinism theory in the media,2011 p26.)

The relationship between culture and technology is an issue that goes back to the beginning of the Industrial Revolution, and some researchers believed that technology would overwhelm everything cultural, and it will become a number of skills and techniques. But in the assumptions of the theory, the culture controls the techniques, and culture will not turn into a set of techniques, because culture belongs to both the material and the intangible factor, the intangible includes everything that increases the value of meanings, as for the material, it includes what comes close to the lived reality, such as customs, traditions and construction. And the relationship between them is healthy as long as the moral is a reference in all kinds of

behavior. 
In fact, there is an attraction between culture and means of communication, and the person resorts to the symbolic world presented by the means of communication to escape from his real world, even if only temporarily.

\section{METHODOLOGICAL FRAMEWORK}

The present study is fundamentally rooted inthe findings and insights of structuralism who wrote on the structures of literature, theatre and drama. It uses structuralism as a theoretical framework within which ideas are structurally organized and as a method of analysis by means of which relevant ideas are expounded and illustrated. Here semiotic is part of structuralism. According to Michael Agar (2010) Structuralism is a method of interpretation and analysis of aspects of human cognition, behavior, culture, and experience, which focuses on relationships of contrast elements in a conceptual system. The doctrine of the structuralism that the "structure" is more important than functions(Agar, 2010, p 234).Also,I agree Lisa M. Given in her definition of structuralism, is a theoretical concept that gained particular currency in the 1960s. It has been interpreted in a number of different ways, but a common theme is the prioritization of the explanatory power of linguistic, social and economic structures. (Lisa.M, 2008)

The value determinism theory of media can initially be considered as a "structure". A structure in philosophical interpretation is the meaning of'Total" or "all" consisting of coherent phenomena, each of which depends on its meaning and is determined by its relationship to the other. This is derived from the properties of the structure and the most important of these principles:priory of all over the parts, priority of the relationship over the parts, contextual principle, principle of reasonableness, principle of synchronization and diachronization etc.(Beghoura, 2001, p 101).Structuralism is an integrated school; its approach is multidisciplinary. The structural approach, despite its definite association with a particular theoretical context, has a natural openness that allows it to be relatively independent of theory. From this, the dimensions of the value determinism theory of the media can be understood as a perspective with a structure away from the evolutionary historical context. (Beghoura, 2001, p72)

BeforeI go into the semiotic structural reading of the value determinism theory of media, it is necessary and systematically important to define first the theory (VDT), in order to fully comprehend the dimensions of the theory, and its founding sources.

\section{DEFINITION OF THE VALUE DETERMINISM THEORY OF THE MEDIA}

This theory is due to the contributions of Azziin the field of communication and media sciences, beginning in 1985 . The foundation of (VDT) of media inevitability as a theory came immediately after the following first studies of Azzi: Information Flow: Frameworks and Historical Rooting(In Arabic); The question of research into a research methodology: Reconsideration of Harold Laswell's model ( In Arabic ); Public opinion, "Assabiya" "and "Shura" ( In Arabic); Reality and Imagination in the media binary (In Arabic); Social Control in the Newsroom: A Case Study (In English); Phenomenological sociology: on Wagner's reflections on Shutz (In English) ;Development : Ethical Competence in the Information Age (In English) ; Islam in Cyberspace : Muslim Presence on the Internet (In English); News across the cultures: a comparative study between Two American and Two Algerian Newspapers(In English);Contemporary Sociological Thought and the Communication Phenomenology : Some Cultural Consideration( In English) ; Islamic Media : Decline of the Message in the Media Age (In Arabic)... ( Nassir , 2005, p 23)

It was clear from these initial studies that there is a value dimension shows in the media studies and is not familiar or is not acknowledgedbefore 1985, namely the value media dimension in media studies, in away similar the value determinism of media studies.

Azzi has been engaged in research of the media phenomenon in the Arab region based on contemporary social thought of the 20th century(Structuralism, Symbolic Interactionism, Phenomenalism and Hermeneutics). With it for the first time as well that preoccupation in media sciences comes with Arab-Islamic heritage and modern Muslim scholars. It was Azzi's interest in these methodological and epistemological ... These and other backgrounds that formed the value determinism theory of the media. This theory(VDT) has opened the way for other studies that are in the same context and beyond or outside the ordinary approach in Arab media studies. (Nassir, 2009, p 34)Azzi wrote about the media and the cultural dimension and how the values dissipate under the visual or civilization of the image. He also wrote on culture and the determinism of communication based on value as a reference. Moreover, he wrote on the culture of students and civilization awareness, and he wrote on the journalism training, he analyzed the relationship between media and the disintegration of value in Arab Muslim region, he wrote on Islam in cyberspace(Muslim presence on the Internet). Inthe field of media history, he has described the Press in the grand(big) Maghreb past and present. He contributed to social media ethics as well.The theory was joined by a number of researchers from the Arab world and from Algeria in particular and the theory has become 
global in methodology and concepts. Two normative theories similar to that (VDT)is media social responsibility and communitarian media ethics, which look at what the media should be, in a clear means denouncing any departure from the "norm" or which tends to reinforce the norm.In another way allowing moral evaluation of people and their actions according to criteria of justice and goodness. In the value determinism theory of media "Norm" means "Value" which comes from religion.

From this point of view this theory (VDT) needs to be read carefully, and we have argued that the structural approach is the key to access this theory.

The value determinism theory of the media as a structure includes these following elements: First, Media and communication sciences as a specialty, second, contemporary social thought in the twentieth century as a general culture, third, Arab-Islamic heritage as an identity and fourth, the Holy Quran text in order to understand the media phenomenon from a spiritual perspective. It is now necessary to return to the keys for reading and understanding the value determinism theory of the media based on this structural approach according to the following axes. These axes which will be explained below are:

\subsection{Priory of the theory (VDT) over the parts:}

The structure requires the globally "all" or"total "and this property produces a methodological principle is the globally view of the subject, that the (VDT) of media as a "bloc" or a "body ". In this way the interested reader of the theory logically requires priority of all (theory) over its parts. It is impossible to understand the theory of Azzi without reading all his works or studies, and it is necessary to spend a lot of time reading his studies and research in the field until the vision of the perspective theory (VDT) becomes clear.

The value determinism theory of media is illustrated by the perspective and its elements. Levy Strauss has relied on this principle in his analysisin his book Family structures of Kinship in French (Structure Elementaire de la Parente). Lévi-Strauss was seen in kinship systems only colleges subject to the principle of the priory of all over parts. (Beghoura, 2001, p56)From this idea the Value determinism theory of media is the composite of the studies and research of Azzi in the media science, contemporary philosophical thought, heritage, etc. The number of these studiesare more than fiftyandalmost allof themproceed from one problematicwhich ishow to approachphenomenon of media from values? Azzi, in fact, wroteone study from one perspective, whichhas multiple angles (aspect) andhe has proceededfrom one problematic can be expressed metaphorically here in thisquestion: Is our media problem in the absence of value and is the solutionthrough the return of value?Azzi puts his focus on the determinant"value" inherent or imbedded on the message and the content of the message. In this respect, Azzi is advancing further the ideas of Marshal McLuhan, that is, from the "Medium is the Message" to "the Message is the value" (Nassir, 2005, pp, 42-49). Azzi's statement describes the communication process and concentrates on the possible application of the message as the carrier of cultural and social values that help the individual and society strengthen their moral and civil public manners, both locally and internationally. This is what ought to be reflected positively on the individual's material, and nonmaterial being. (Kareem, 2009, p 29)

If, McLuhan intended to explain the evolution of his society, Azzi with his value determinism theory, also intends to explain his society. This brings me to the following, that the notion of cultural relativity is very important and significant, as well as the notion of normative theory. more particularly, in some of comparative studies and research. This is becoming evident by the works of both McLuhan and Azzi that mass communication theory and study ought to make account of cultural and social relativity factors as well as of normative theories. The theory and practice of mass media ought to be based on those culturally, historically, and socially determined factors as well as on the materially and nonmaterially determined characteristics of society. Therefore, the message is more determined by its value, rather than by its medium, and that "the message is the value" (Nassir, 2005, p17).

The media problem is the dependent variable on which the impact may occur, and the value is the main independent variable from which the effect (Impact) is generated negatively or positively. In this respect the question is how to approach or distance the media from value? Azzi's research on value media can be categorized ascontemporary social thought,Journalism,masscommunication,public

relations,communication technology,journalism training,communication theories,communication research,media ethics, studies of personalities from a value perspective("Al Nursi5", "Al Wartilani'", "Sun Tsu", "Abu Hammed Al Ghazali" "...) as well as its various translations. Inaddition, he has many books and what he was written about his contributions and his value's theory.

The studies of Azzi are elements within all of the previous domains (units). These areas contribute to the formation of the theory (VDT). The Value determinism theory of media is the context format of these units. Godolet emphasized this principle saying that the part is entirely conditional of 
the all (Godolet, 2010, p 234). From there, it can be said that the perspective of understanding the value determinism of media depends on the principle or approach of all rather than the principle of partiality. This last principle may help not only to partially understand some studies of Azzi, the author of the theory, but it does not help us to understand the theory as an integrated structure and harmonious format.

\subsection{Priority of the Theory Relationship over the Parts:}

The concept of structure is related to the concept of relationship within a context format, and what is interested or related to structuralism is not events or words in isolation, but the relationship that exists between those events or words. Moreover, in this approach it cannot be considered as the value determinism theory of media as these are isolated studies and separated from each other, but it is necessary to see the relationship between these studies. The Value determinism theory of media becomes clearer as we look closely at the strands that tie his contributions. Therefore, knowledge of the relationship among the studies of Azzi is essential to understand the meanings of the theory. we have already registered in a previous study that the studies of Azzi are a series of interconnected loops and that there is a high-level thread that forms a link between all these episodes, and this thread is the civilization tendency filled with thought and transcendental perceptions. For example, those relationships link parts of the theory and make it coherent. A good reader can observe, for example, that "the importance of news" in the treatment of journalism constitutes as a concept of a relationship between his following research: "Information Flow: Reference Frameworks and Historical Rooting ", "Social Control in the Newsroom," "Cross-Cultural News," "Arabicmedia, An Evaluative Reading of the William Rugh theory", "In the code, Press and semiology", and "Maghreb Arab Press "... These studies are linked to one another by giving importance to news that provide information and separate the news from opinion, and the emphasis of Azzi is on the importance of information in journalism practice. The studies of value determinism theory of media, which are concerned on the "message" as a relationship are in these studies respectively:" Crisis of the Message in the Algerian Media System", "Student Culture, Civilization Awareness and Communication", "Communication and the Rural World: The Crisis of the Message", "The Impact of Media on the Value System in the Intermediate Rural Society", and "Multimedia and Communication Curricula: The Medium Vs the Message", etc. Teaching in the field of media as a relationship between two important studies are: "Media Teaching, Convergence and Cancellation between the Medium and the Message," : an Applied Study on a Sample of Students of the Department of Communication Sciences of University of Algiers, and the second studyis titled "Media Science and the Value Dimensions " which is a case study using content Analyses of the courses taught by students in the same department, It was concluded that The programs and courses in this department work not on the values of students, but on distorting their values because the vocabulary of the courses is not contextual and also distinct from the specificities of the training. In addition to the absence of interactive relationship in the courses and program component parts between the goals and the mission and vision.

Media theory comes as a value in his research on contemporary social thought in the twentieth century. " The value determinism theory of media manifested as a verb or a big idea in the twentieth century requiring the foundation in his study of "Reality and fiction in the media binary", there are many signs of value determinism theory in the following studies: "Social theories on the twentieth century and Ibn Khaldun" reflections" ; “ Post Structuralism and Arab cultures" ; " the phenomenological school and Arab life Space "; "Islamic Media : the Decline of the message in Media Age" ; "Symbolic Interactionism and the Reality of Arab Symbolic Life" : "Hermeneutical Analyses and Arab Institutional Structure" etc.

In his book, "Studies in Communication Theory: Towards a Distinguished Thought in Communication" (In Arabic),Azzi introduces us to new concepts not known or unfamiliar in media studies such as the following: Media Imagination, Media location, Media time, Media Fear, Capital of media symbolic, Biological impact of media, Hearing and Sight and the fact of communication, Violence of speech etc. Also we can observe that the Deontology or the Ethical constitutes a relationship between the following studies: "Media law and Ethics in the Context of Social Media: Readings in the Value System ";" Ethical Duty theory in media practice" and "the Morality of Journalism Ethics: Reading in Nurse's Theory of God's Attributes". The latest research on the theory we find the value as a dependent variable in the following study: The Archeology of Value-oriented Communication Thought: Readings in Malek Bennabi, Al Warthailani, Al Nursi and Sun Tsu.

Finally, the "value" is the structural relationship that connect all of these concepts and Studies and make them projected only within the structure of the theory, and the use of the term" Determinism" as the title for theory 
(VDT), evidence of the close relationship of value in these perspective.

\subsection{The Value Determinism Theory of Media as a Context:}

The Principle of contextual is never to ask for the meaning of a word in isolation, but only in the context of a proposition, and never to lose Sight of the distinction between concept and object(Kareem, 2009, p 19). According to this, the elements of the value determinism theory of the media have no meaning as separate entities but acquire significance within the general context so it is like a poem. In order to understand, a poetic verse must be put it in relationship with other verses of the poem; otherwise the meaning will be disturbed. For a good understanding of the value determinism theory of the media, one part of the theory should not be read, and the other parts ignored or in isolation. The theory is like musical symphony chime in it all the tunes.

The principle of contextual analysis is for the presence of social, cultural, civilization and historical factors that helped and built up this theory (VDT). we believe that the environment that Azzi belonged to, the nature of his religious formation, his study in America, his contact with the founders of Western theories communication (Twostep Flow of Communication, Agenda Setting, Uses and Gratification and the founder of American Pragmatism)and his studies on media heritage are the factors that constitute the external context of the value determinism theory of the media, and we say that the understanding of this theory is not in isolation from the understanding of the general direct and indirect context in which the theory was formed and which moves within the researcher. The theory has many contextual dimensions, and a good understanding of it is necessary to take part, at least partly, the structure of contemporary philosophical and social thought suchas the symbolic interactionism school, the phenomenological school, the structuralism and post structuralism school, and the Hermeneutics school, etc. The structure of normative communication theories such as the social responsibility theory and the communitarian media ethics theory; Media determinism theory from Marshal McLuhan; Theory of geographic determinism from Ibn Khaldoun; and the contributions of Malek ben $\mathrm{Nabi}^{10}$ to the problems of civilization in Arabi Islamic World. Ethical duty theory in media practice is a partial theory within the value determinism theory of media, where it is also a new context of the theory (VDT) and represents a qualitative transfer from "Social Responsibility" to "Moral or ethical Responsibility". That's mean the ability to recognize and act upon multiple principles and values according to the standards within a given field and/or context. For example, Journalists explore various complexities, dynamics and issues surrounding behavior and ethical practices in order to understand best ways to make decisions and resolve issues at personnel, group and societal levels.

The reader is associated with the research and studies of value determinism theory of media whenever it is related to the previous contexts, which carries him it to know the manifestations of the media phenomenon and its internal and external components, and the reader is not associated with the meanings, connotations and concepts of the (VDT), but may find it inaccessible if he does not understand these contexts or that it is far from, and this Structurally, in order to understand the meaning of the word, must be placed in the context of its general context, as Ferdinand de Saussure mentioned in his study as “ Elements of general linguistics", which is written in French " elements de l'inguistique general".

And in the context of revealing differences related to international communication, Professor Azzi believes that: (Azzi Abderrahmane, The methodology of value determinism in the media, 2013, p 49) for example:

How do newspapers in two different societies in covering the same event. The same applies to a comparison between the media, forexample: How does the acting performance differ in radio drama and that in cinema?

It should be noted in this research to mention essential component related to the value determinism theory, relates to the study of the existing or absent value capital in the media or audience. (Azzi Ibid, p. 50)Therefore, content analysis can be defined in this theory as follows:

Content analysis is a quantitative and qualitative method that seeks to study the presence of values Directly or indirectly, in the contents of the traditional and new media and the impact of this on the audience of recipients, either positively or negatively

With the aim of knowing the degree of relevance of these methods to community values and their relationship to civilizational and social development.

The above contexts lead to a basic objective which is to know the structure of the theory from within. The value determinism theory of the media is a big perspective that it turned out that they do not exist on the surface of their perspective, but rather discover the theory through the internal structure and the relationship of this structure to the various external contexts.

\subsection{The VDT of Media and the Dichotomy of Synchrony Vs Diachrony:}

The VDT appeared at a time when the southern hemisphere suffered many communication problems, it was 
in the seventies and eighties of the last century. The MacBride Report entitled "Many Voices, One World: Communication and society today and tomorrow "explained this synchronous period in detail, the report aimed to establish a new global information system. In another way: towards anew more just and more efficient world information and communication order. The solutions proposed were all aimed at addressing the problem of the "free flow of information" and eliminating the imbalance between the North and South in the field of media and communication. The MacBride Report evoked a storm of criticism from Western media, and was a catalyst in the decision of the U.S. And U.K. to leave UNESCO. During this synchronous period and with the same media problems that the world lives in, Azzi has worked on the subject of disinformation "News Across the Cultures" between North and South, he wrote a comparison study between two American Newspapers (New York Time and the Christian Science Monitors daily) and two Algerian Newspapers (El Moudjahid and El Djemhouria daily newspapers. This study on the reporting of international news in two Algerian and United States Daily Newspapers, diagnosed the free flow of information between North represented by U.S and South represented by Algeria. This study was classified as among the studies that dealt with the problem of media dependency. It has appeared in this synchronous period where many media concepts emerged: cultural invasion, media imperialism, etc.,on the same meaning of media dependency. It also appeared in the same time in the Islamic world some media concepts related to the Islamic communication tradition... The (VDT) of media offered the Value as an alternative. It was done firstly in the following translated studies:Mass Media today and tomorrow (1991), for the author Leo Bogart, Mas media in the third World (1992), for the author John Lent, Occidental Media and the Third World (1988), for the author Ralf Lowenstein, and his (Azzi) twostudies, News flow: reference frameworks and the Historical rooting, Media and civilization dimensions (presented as a conference in the first collogue of Media and Disinformation (Algiers, 1987). The second step of the (VDT)related to linking the media phenomenon with contemporary social and philosophical thought in the Arabic context. This period was needed a deeper understanding of the media phenomenon, rather reflects the meanings inherent in the text.

\section{CONCLUSION}

This methodologic structural approach of the media value determinism theory (VDT) does not mean we have understood the epistemological context of the theory. The epistemological aspect of the theory needs a deeper review of the studies that we have mentioned in the topic. Actually, the number of studies which is related to the theory exceeds 50 studies. These studies also need to be clarified and classified according to the topics of each study and according to the time of its publication and linking it to the phenomenon of media in the region and abroad. Now the (VDT) affiliated to a group of researchers in the Arab \& Muslim world and represents a scientific school has its background knowledge and also represents the epistemological rupture with the old contexts and concepts in the field of media studies.

\section{Notes:}

1. Azzi's theory is an important cultural, intellectual, media production who can only be understood by reading the minutest details of Izzi's books and research studies of those interested in theory searched for it.

2. Many concepts and terms in the theory seem difficult to understand but once you read it carefully You can understand it and its future prospects in media research.

3. This theory (VDT) of media is characterized in July 2012 as a BIG IDEA for the past 100 years, through research competitions, conference panels and scholarly journals, by AEJMC News. aejmc.org/home/publications/aejmc news

This new idea views "Values", whose essence are "morals" as a basis to measure media's impact on society. The theory draws on communication theoretical heritage of both western and non Western context; thus it claims universality. This theory is praised and commented by eminent media scholars such as Prof. Christians g. Clifford, Prof. Max Macomb's, author of Agenda - Setting Theory, and Prof. Em Griffin.

4. Abderrahmane Azzi has more than 30 years of teaching, research and supervision experience. He has worked as a teaching assistant for three years at the University of North Texas (NTSU), where he was recognized for teaching excellence. Then he has worked as a Professor at the University of Algeries (Algeria) for eleven years. After that he has worked as a Professor for three years at International Islamic University in Malaysia, then he has worked as a professor of mass communication at King Saud University in Riyadh for four years, then a chair of the department of mass communication for four years at UAE University. He is currently a Professor at the University of Sharjah. Abderrahmane Azzi is the author of many books, research and studies in Media and communication in both Arabic and English. He 
received Ben Badis Prestigious Awards from University of Mostaganem (Algeria) for his contribution to ethical communication. $\mathrm{He}$ is currently working on ethical theory; cross- cultural comparative analyses and translating his work on VDT into English.

5. Assabiya(concept Arabic), represents "social cohesion" in Arabic. This concept is used by the Arab middle agephilosopher Abderrahmane ibn Khaldoun, who described Arab cultural and territories. This term refers to social solidarity with emphasis on unity, group consciousness, and social cohesion. It is, originally, a term used in a tribal or clan context, but according to certain meanings it can also refer to modern nationalism, in a way similar communitarianism. It is a familiar concept in the preIslamic era it was popularized by Ibn-Khaldun's prolegomena which describes it as the fundamental link of human society, and the main force for setting history in motion. Assabiya is not necessarily nomadic or based on Blood ties, it is closer to classical republicanism. Now the term "Assabiya"can be synonymous with solidarity. However, it often has a negative connotation, because it places loyalty above circumstances.

6. AIShurra(term Islamic), consultation "council ", means in particular the parliament of an Islamic state, the Board of directors of a party or of religious institution. In the Muslim religious context is council of Musulman judges.

7. SaidNursi (Turkish: Said Nursi) Known as "Badie Zaman Nursi ", a Kurdish Muslim scholar of the Aspartite Clan (1877 - 23 Marsh 1960), one of the most prominent religious and social reform scholars of his time. He was born in the Kurdish village of Nawras during the Ottoman Caliphate.

8. Sheikh Al Hussain Al _ Warthailani, Author of the Famous Tour (Travel) A Sight-seeing in the merits of history science and news. That journey includes more than 700 pages, in addition to being an art that like News reporting in expression.

9. Sun Tsu or Sun Zi (Chinese). He is the best known as the author of the oldest known military strategy book: The art of the War. The main idea of his work is that the objective of the war is to force the enemy to abandon the fight...

10. Abu Hammed Al-Ghazali was one of the most prominent and influential Muslimphilosophers, theologians, jurists, mystics of SunnaIslam, he was of Persian origin. Some Musulman consider him to be a "mujad did", a renewal of the faith who according to the prophetic hadith, appears once every century to restore the faith of the Ummah "the Islamic community ". His works were so haitly acclaimed by his contemporaries that al Ghazali was awarded the honorific title "Proof of Islam "Hujjat al Islam".

\section{REFERENCES}

[1] Agar, Michael. (2010). On the Structuralism part of the mix. Amulti- genre taleof the field. Organizational methods, 13(2), 222- 256.

[2] Azzi, Abderrahmane (2003). Studies in Communication Theory towards Distinct Media Thought. Series 28. First Edition. Beirut: Center for Arab Unity Studies.

[3] Azzi, Abderrahmane (1994). Reality and fiction in the media binary. The Arab Future Journal, 16(1), 56 - 80.

[4] Azzi, Abderrahmane (2011). An Invitation to understand the VDT of Media. First edition, Tunisia, Al Moutawasitia Publishing.

[5] Bouali, Nassir (2009). Media between MarshalMc-Luhan and Azzi Abderrahmane, fromTechnologytoMoral competency. Al hikma Journal, 4(4), 12 -30.

[6] Bouali, Nassir (2005). Media and values, a reading in the theory of the Algerian thinker Abdel Rahman Azzi. First Edition. Algeria: Al Huda Publishing House.

[7] Bouali, Nassir (2007). Media and the civilization dimension, studies in the media and values. First edition. Algeria: Al Fadjr Publishing House.

[8] Bouali, Nassir (2009). Readings in the Value determinism theory of the media. First ed. Algeria: Ikraa Publishing House.

[9] Clifford, G. Christians (2019). Media Ethics and Global Justice in the DIGITAL AGE. 1 ed. United Kingdom: University Printing House.

[10] Lisa M. Given. (2008). the sage encyclopedia of Qualitative research methods. Volume 2. Sage publishing.

[11] Mohamed, Kareem Hashim (2009)., A theoretical road less traveled, Mathematical theory, Media Determinism and Value Determinism, First edition. Algeria: Ikraa House.

[12] Zawawi, Beghoura (2001). Structural Approach, Research in Origins, Principles and Applications. First Edition. Algeria: Al Huda Publishing House. 